\title{
Minor Axis Internal Diameter at End Ventricular Diastole
}

National Cancer Institute

\section{Source}

National Cancer Institute. Minor Axis Internal Diameter at End Ventricular Diastole. NCI

Thesaurus. Code C139061.

The internal diameter of a cardiovascular structure measured along its minor axis at end ventricular diastole. 